\title{
Biological profile of ameloblastoma and its location in the jaw in 1246 Nigerians
}

Jimoh Olubanwo Agbaje, $\mathrm{PhD},{ }^{\mathrm{a}}$ Akinyele Olumuyiwa Adisa, FMCDS, ${ }^{\mathrm{b}}$ Mariya Ivanova Petrova, $\mathrm{PhD},{ }^{\mathrm{c}}$ Adeola Adenike Olusanya, FMCDS, ${ }^{\mathrm{b}}$ Tolulope Osayomi, PhD, ${ }^{\mathrm{d}}$ Olajumoke Ajibola Effiom, FMCDS, ${ }^{\mathrm{e}}$ Olujide. Oladele Soyele, FWACS, ${ }^{\mathrm{f}}$ Olufemi Gbenga Omitola, FMCDS, ${ }^{g}$ Adetokunbo Babajide Olawuyi, FMCDS, Robinson Obos Okiti, BchD, ${ }^{\mathrm{b}}$ Thelma Eziafa Saiki, BDS, ${ }^{\mathrm{b}}$ Benjamin Fomete, FWACS, ${ }^{\mathrm{h}}$ Adebayo Aremu Ibikunle, FWACS, ${ }^{i}$ Chuckwubuzor Okwuosa, BDS, ${ }^{j}$ Mofoluwaso Abimbola Olajide, FMCDS, ${ }^{k}$ Adeola Mofoluwake Ladeji, FMCDS, ${ }^{\mathrm{k}}$ Kehinde Emmanuel Adebiyi, FWACS, ${ }^{\mathrm{k}}$ Mubarak Mobola Emmanuel, FMCDS, ${ }^{\mathrm{k}}$ Hammed Sikiru Lawal, FMCDS, ${ }^{1}$ Emeke Uwadia, FMCFD, ${ }^{1}$ Babatunde Oludare Fakuade, FMCGD, ${ }^{\mathrm{m}}$ Yusuf. Mohammed Abdullahi, FWACS, ${ }^{\mathrm{m}}$ and Constantinus Politis, $\mathrm{PhD}^{\mathrm{a}}$

Objectives. Ameloblastoma is a benign, slow-growing, locally invasive epithelial tumor of odontogenic origin, with unlimited growth capacity and a strong tendency to recur. This multicentric study analyzed ameloblastoma diagnosed in Nigeria among different ethnic groups.

Study Design. This retrospective study included ameloblastoma cases diagnosed from 1964 to 2017 at 10 hospitals or medical centers in Nigeria. Age, sex, tribe, and location of the ameloblastoma in the jaw were analyzed. Associations between variables were tested by using $\chi^{2}$ and Fisher's exact test.

Results. A total of 1246 ameloblastoma cases were recorded (mean patient age $32.51 \pm 14.54$ years; range 4-86 years; male-tofemale ratio 1.2:1). Approximately $60 \%$ of ameloblastoma cases occurred in young adults (age range 18-40 years). Ninety-eight lesions were located in the maxilla and 1103 in the mandible; the posterior mandible was the most common site $(31.3 \%$ on the right and $26.5 \%$ on the left, respectively), followed by the anterior $(26.0 \%)$ mandible. No significant differences were noted in the distribution of ameloblastoma within the tribes with respect to age $(P=.92)$ and sex $(P=.71)$.

Conclusions. The mandible is a common site of ameloblastoma in patients in Nigeria, and in most cases, it occurs in young adults. Early presentation, diagnosis, and treatment are important to reduce postoperative disfigurement and morbidity. (Oral Surg Oral Med Oral Pathol Oral Radiol 2018;000:1-8)

Ameloblastoma is a benign, slow-growing, locally invasive epithelial tumor (with no ectomesenchymal component) of odontogenic origin, with a strong tendency to recur after treatment. The tumor occurs exclusively in the jaws, with a tendency to cause gross facial deformity and tooth displacement. Ameloblastoma has been found to be the most common odontogenic tumor-if odontomas, which

${ }^{a}$ OMFS-IMPATH Research Group and Department of Oral and Maxillofacial Surgery, Katholieke Universiteit Leuven, Belgium.

${ }^{\mathrm{b}}$ University College Hospital, Ibadan, Oyo, Nigeria.

${ }^{\mathrm{c}} \mathrm{KU}$ Leuven, Centre of Microbial and Plant Genetics, Leuven, Belgium.

${ }^{\mathrm{d}}$ Department of Geography, University of Ibadan, Ibadan, Nigeria.

e Lagos University Teaching Hospital, Lagos, Nigeria.

f Obafemi Awolowo University Teaching Hospital Complex, Ile-Ife, Osun, Nigeria.

${ }^{\mathrm{g}}$ University of Port-Harcourt Teaching Hospital, Port-Harcourt, Nigeria.

${ }^{\mathrm{h}}$ Ahmadu Bello University Teaching Hospital, Zaria, Kaduna, Nigeria.

${ }^{\mathrm{i}}$ Usman Danfodiyo University Teaching Hospital, Sokoto, Nigeria.

${ }^{\mathrm{j}}$ University of Nigeria Teaching Hospital, Ituk-Ozalla, Enugu, Nigeria.

${ }^{\mathrm{k}}$ Lagos State University Teaching Hospital, Lagos, Nigeria.

${ }^{1}$ Federal Medical Center, Birnin Kudu, Jigawa, Nigeria.

${ }^{\mathrm{m}}$ Federal Medical Center, Gombe, Nigeria.

Received for publication Jan 11, 2018; returned for revision Jun 15, 2018; accepted for publication Jun 23, 2018.

(c) 2018 Elsevier Inc. All rights reserved.

2212-4403-see front matter

http://doi.org/10.1016/j.0ooo.2018.06.014 are generally regarded as hamartomas or developmental anomalies, are not considered—constituting approximately $1 \%$ of all oral tumors and $12 \%$ of odontogenic tumors. ${ }^{1}$ In Africans, ameloblastoma is estimated to account for $11 \%$ to $24 \%$ of all oral tumor-like lesions. ${ }^{2-4}$ The prevalence rate could increase to $40 \%$ to $84 \%$ of odontogenic tumors when odontomas are not included or in centers where odontomas are not commonly diagnosed. ${ }^{3,5-7}$

Ameloblastoma has a high capacity to infiltrate between the trabeculae of cancellous bone, leaving cortical bone intact for some time. Thus, the tumor is usually present for some time before the patient presents with symptoms. Pain is rare and occurs mostly as a result of secondary infection or compression of a nerve. Consequently, those who are affected are usually reluctant to seek medical or dental care. However, ameloblastoma has an unlimited growth capacity and, if left untreated, can grow into a large tumor mass,

\section{Statement of Clinical Relevance}

Ameloblastoma is a common tumor occurring in the young adult population of Nigeria. Late presentation for treatment is common, but early presentation, diagnosis, and treatment are important to reduce postoperative disfigurement and morbidity. 
disfiguring the facial region. Various studies in Nigeria have shown that patients with ameloblastoma present late for treatment, resulting in delay in treatment and severe disfigurement of the facial region, sometimes with functional impairment. ${ }^{8-12}$ Mortality in ameloblastoma is a rare occurrence, but a few deaths resulting from late presentation have been documented. ${ }^{12}$ Therefore, the need for public enlightenment on the nature and treatment of facial tumors, such as ameloblastoma, is important.

The current predominant mode of treatment for ameloblastoma is surgery (jaw resection), which can be conservative or radical. However, studies have shown that conservative treatment of ameloblastoma, such as curettage and enucleation, may lead to recurrence rates as high as $90 \%$ for mandibular tumors and $100 \%$ for maxillary tumors. ${ }^{13-16}$ Radical treatment entails surgical resection of the affected part of the jaw with the associated neurovascular bundle, followed by reconstruction; this mode of treatment is usually associated with better results and a low recurrence rate. ${ }^{13,14,17}$ Surgical management of ameloblastoma has a profound functional and psychological effect on patients' quality of life, ${ }^{18}$ and jaw resection is usually accompanied by complications, such as facial deformity, nerve damage, malocclusion, and impairment of mastication. ${ }^{10}$

Several regional studies have been carried out on the relative frequencies, incidences, clinical features, and treatment of ameloblastoma in different parts of Nigeria, but a national multicenter study has yet to be performed. The objective of this study was to analyze diagnosed cases of ameloblastoma in a multicentric study among the Nigerian population. We performed an analysis of a series of ameloblastoma cases diagnosed in hospitals and medical centers in Nigeria, including tumor frequency, age, sex, and the site of occurrence in the jaw. Certain factors may be used to encourage patients with ameloblastoma to seek early treatment and, thus reduce postoperative disfigurement and morbidity.

\section{MATERIALS AND METHODS Study design}

This retrospective study included ameloblastoma cases histologically diagnosed from 1964 to 2017 at 10 hospitals or medical centers in 5 of the 6 geopolitical regions (southwest, south-south, southeast, northwest, and northeast) of Nigeria: Lagos University Teaching Hospital, University College Hospital in Ibadan, Obafemi Awolowo University Teaching Hospital Ife, Usman Danfodiyo University Teaching Hospital in Sokoto, Ahmadu Bello University Teaching Hospital in Zaria, University of Nigeria Teaching Hospital in Enugu, University of Port-Harcourt Teaching Hospital,
Lagos State University Teaching Hospital Lagos, Federal Medical Center in Jigawa, and Federal Medical Center in Gombe. Data from the north-central region was not available at the time of analysis. Approval was obtained from the ethics committees of all participating hospitals and medical centers before commencing data collection. Data on age, sex, tribe, and the location of ameloblastoma in the jaw were collected and analyzed. Data on tribes were obtained from each patient by participating centers at first contact. The obtained data were categorized by tribal groups included in this study.

Regarding tumor location, tumors in the maxilla were grouped as follows: anterior maxilla, posterior right maxilla, and posterior left maxilla. Tumors in the mandible were grouped into anterior mandible and posterior mandible, right and left sides. This grouping was used mainly for the analysis. In some cases, the tumor extended across 2 or more grouping sites.

\section{Statistical analysis}

Patient characteristics are presented by using descriptive statistics. Counts and percentages were used to summarize categorical variables. Mean, standard deviation, and range were calculated for variables of interest. Statistical analyses were carried out by using SAS, version 9.4 (SAS Institute Inc., Cary, NC). Associations between variables were tested by using the $\chi^{2}$ test. For data with less than 5 observations association between variables were tested using Fisher exact test. The level of significance was set at $P<.05$.

\section{RESULTS}

A total of 1246 ameloblastoma cases presented to the 10 health facilities were analyzed.

\section{Age}

Mean age at presentation was $32.5 \pm 14.5$ years $(32.7$ \pm 14.7 years in females and $32.4 \pm 14.5$ years in males; range 4-86 years). Mean age of patients with lesions in the mandible was $32.1 \pm 14.2$ years, whereas mean age of patients with lesions in the maxillae was $35.4 \pm 17.8$ years (Figure 1). No significant differences were observed for age distribution between mandible and maxilla $(P=.12)$. Mean age of patients with peripheral ameloblastoma was $44.8 \pm 11.5$ years.

\section{Sex}

Lesions were detected in all ages in both sexes, with males representing $54.4 \%$ (678 of 1246) of all patients seen (560 of 1246 females [44.9\%]; male-to-female ratio 1.2:1). The sex was not stated for 8 patients. More than half of all cases occurred in young adults, with similar male-to-female ratios among all age groups except in childhood (Table I). 

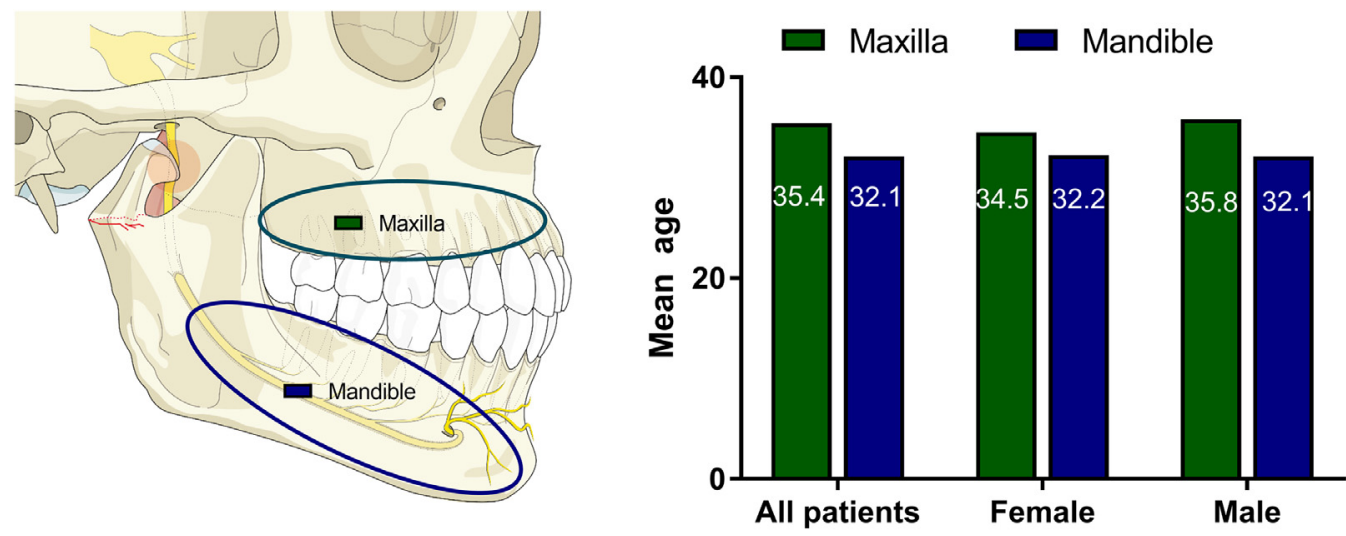

Fig. 1. Mean age of patients with ameloblastoma in the maxilla and mandible at presentation.

\section{Tumor sites}

A total of 98 lesions were located in the maxilla, whereas 1103 lesions were located in the mandible, resulting in a maxilla-to-mandible ratio of 1:11.3. Thirty-six cases of ameloblastoma were not categorized to the upper or lower jaw, and 9 cases occurred in soft tissue. Figure 2A shows the distribution of lesions in the jaw, with the posterior mandible being the most common site (379 of 1210 cases [31.3\%] on the right and 320 of 1210 cases [26.5\%] on the left), followed by the anterior mandible (315 of 1210 [26\%]). The least number of cases was observed in the anterior maxilla (22 of 1210 [1.8\%]). In the posterior maxilla, $63.2 \%$ (48 of 76) of the tumors occurred on the right. The site distribution of tumors in males and females are shown in Figures 2B and 2C, respectively.

The site distribution of ameloblastoma in the different age groups is presented in Figure 3. The distribution of ameloblastoma in the jaw seems to follow a similar pattern in all age groups $(P=.10)$, with the posterior mandible being the most common site.

\section{Tribe}

The site distribution of ameloblastoma among different tribal groups in Nigeria is presented in Figure 4A. The Yoruba tribe had the highest number of lesions, followed by the Igbo and Hausa tribes (Table II). Figure 4B is a heat map of locations of ameloblastoma in the jaw in patients from the different tribes in Nigeria. Fisher's exact test for the association between tribes and jaw segments showed significant association $(P=.03)$.

Mean age and the male-to-female ratio for each tribe are presented in Table II. The 3 major ethnic groups in this study had a peak frequency of ameloblastoma occurrence in the third decade of life, with patients from the Yoruba tribe presenting 2 years later than those from the Igbo and Hausa tribes. However, no significant differences were observed in the distribution of ameloblastoma within the major tribes (Yoruba, Igbo, and Hausa) with respect to age and $\operatorname{sex}(P=.76, .73$, and .99 , respectively).

\section{DISCUSSION}

This article presents the results of a multicenter analysis of diagnosed cases of ameloblastoma from different geopolitical zones and tribes in Nigeria. The peak age of occurrence of ameloblastoma was in young adulthood, a finding that has been similarly reported in other Nigerian publications, ${ }^{8,19}$ followed by adulthood and adolescence. The male-to-female ratio was similar to that reported in other studies performed in Nigeria, ${ }^{10,20,21}$ Northern Brazil, ${ }^{22}$ and India, ${ }^{23}$ but slightly different from that in studies in Malaysia, South Korea, and China (male-to-female ratio $1.4: 1){ }^{24-26}$

We found fewer lesions in the maxilla than in the mandible, which is similar to the findings from the Chinese population, which has a reported maxilla-to-mandible ratio of 1:4. ${ }^{25}$ In addition, tumors in the maxillae

Table I. Age group and sex distribution in ameloblastoma cases

\begin{tabular}{lllll}
\hline Age group & Male & Female & Male-to-female ratio & Total \\
\hline Childhood ( $\leq 10$ years) & 8 & 10 & $0.8: 1$ & 18 \\
Adolescence (11-17 years) & 74 & 60 & $1.2: 1$ & 134 \\
Young adult (18-40 years) & 411 & 336 & $1.2: 1$ & 747 \\
Adult (41-65 years) & 145 & 116 & $1.3: 1$ & 261 \\
Elderly ( $>65$ years) & 20 & $172: 1$ & 37 \\
Uncategorized & & & & 49 \\
\hline
\end{tabular}




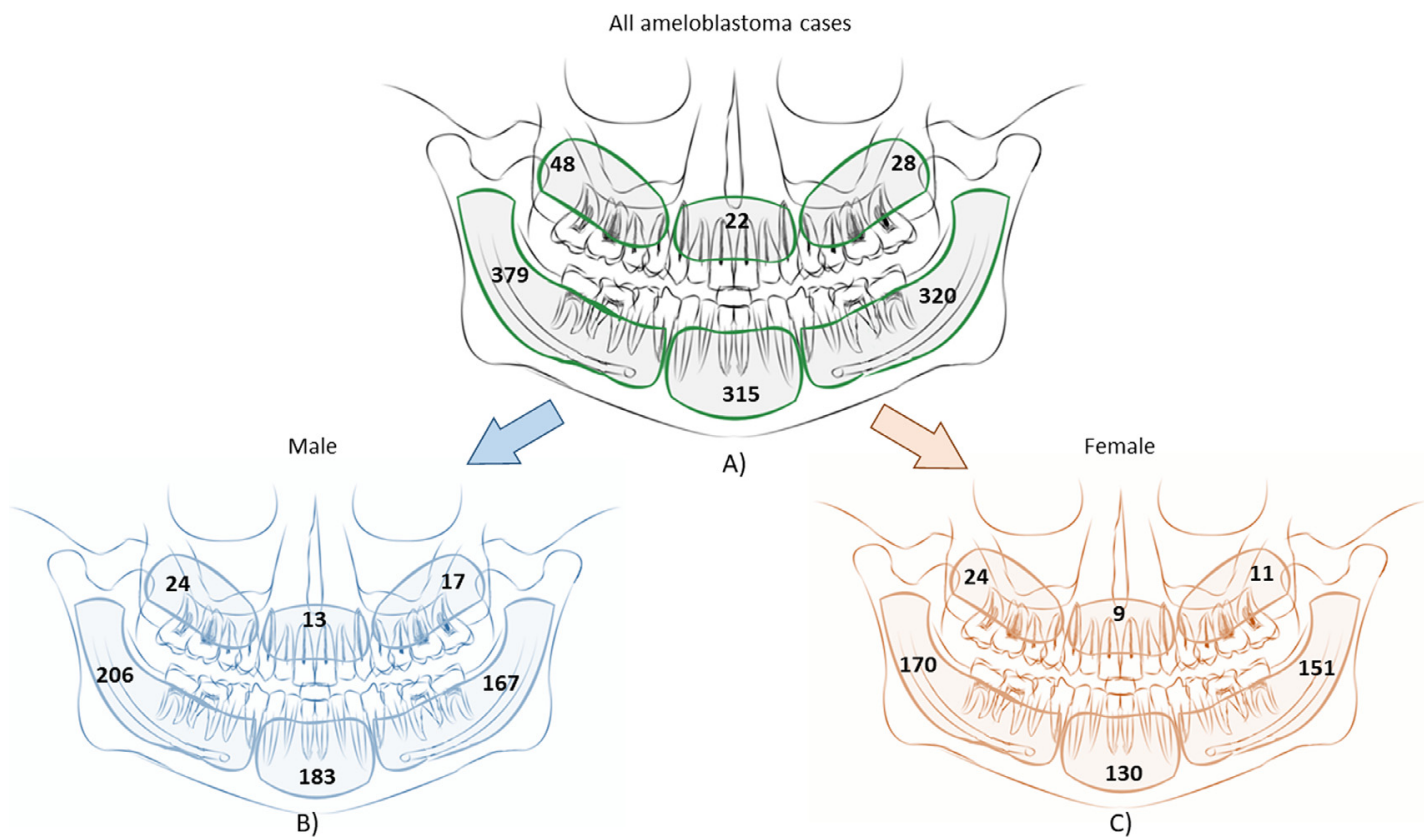

Fig. 2. Locations of ameloblastoma in the jaw. A, All ameloblastoma cases; 1103 cases were detected in the mandible, 89 of which were not categorized into an exact region and, therefore, are not shown in the figure. $\mathbf{B}$, Locations of ameloblastoma in the jaw in male subjects. $\mathbf{C}$, Locations of ameloblastoma in the jaw in female subjects.

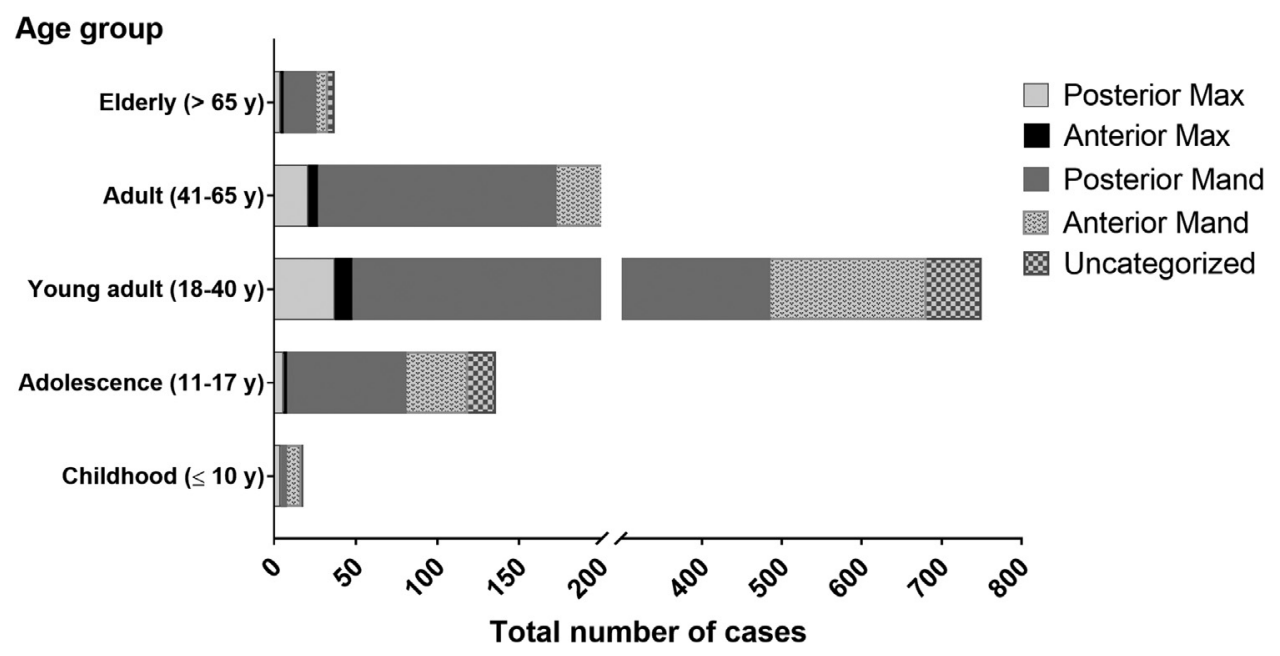

Fig. 3. Age group and site distribution of ameloblastoma in all subjects. mand, mandible; max, maxilla.

in this study appeared to occur 3 years later than those in the mandible. In the present study, the posterior regions of the mandible were the most common sites of ameloblastoma, accounting for $26.5 \%$ to $31.3 \%$ of all cases in the jaw, followed by the anterior region of the mandible. This finding is in agreement with previous studies performed in a different part of Nigeria. ${ }^{5,6,9,20,27}$ Peripheral ameloblastoma occurred in only 9 cases, accounting for $0.7 \%$ of all cases, which is low compared with the previous findings by Olaitan et al., ${ }^{27}$ who reported 4 (1.3\%) of 315 cases of ameloblastoma in the soft tissue in patients seen at the Ahmadu Bello University Hospital, Kaduna, Nigeria, with an incidence of $2 \%$ to $10 \%$, as reported in the literature. $^{28,29}$ The average age at presentation of peripheral ameloblastoma was 44 years in this study, whereas the average age reported in the literature was 52 to 54 years. ${ }^{28,29}$

The age of patients at presentation and the locations of ameloblastoma in the jaw were similar in all tribes, 
A)

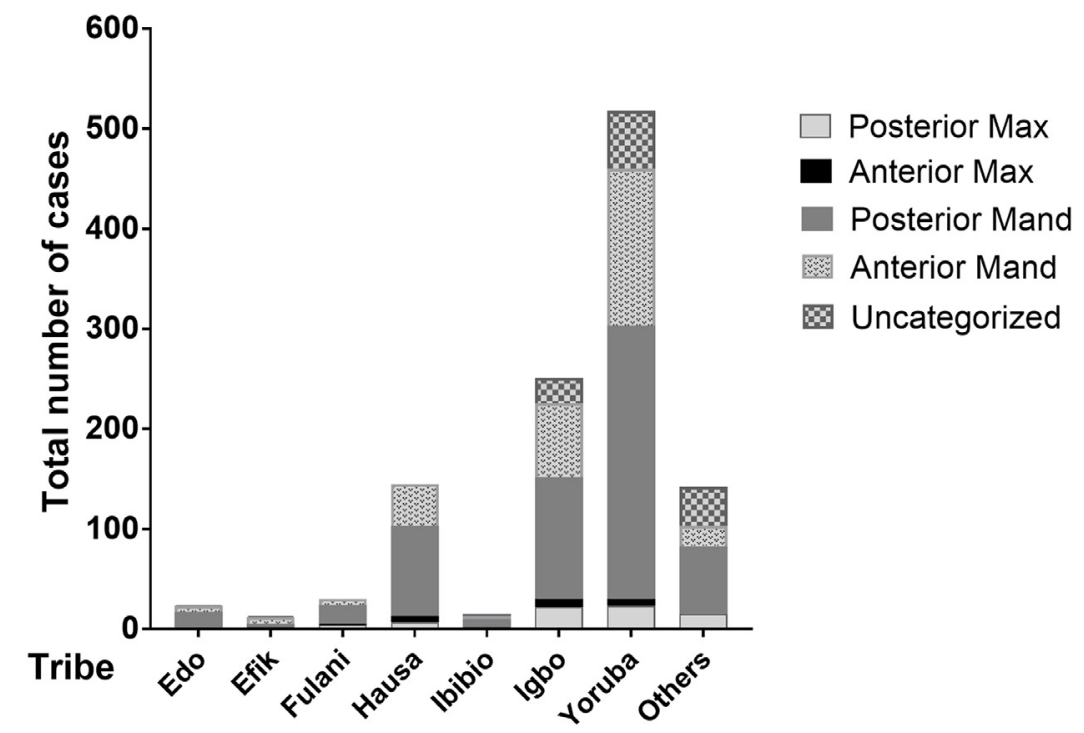

B)

\begin{tabular}{|l|l|l|l|l|l|l|}
\hline Tribe & $\begin{array}{l}\text { Anterior } \\
\text { Mand }\end{array}$ & $\begin{array}{l}\text { Anterior } \\
\text { Max }\end{array}$ & $\begin{array}{l}\text { Posterior } \\
\text { Mand }\end{array}$ & $\begin{array}{l}\text { Posterior } \\
\text { Max }\end{array}$ & $\begin{array}{l}\text { Soft } \\
\text { tissue }\end{array}$ & Uncategorised \\
\hline Edo & 0.5 & 0 & 1.3 & 0.1 & 0 & 0.1 \\
\hline Efik & 0.6 & 0 & 0.3 & 0.2 & 0 & 0.1 \\
\hline Fulani & 0.5 & 0.1 & 1.5 & 0.3 & 0 & 0 \\
\hline Hausa & 3.4 & 0.5 & 7.2 & 0.5 & 0 & 0 \\
\hline Ibibio & 0.2 & 0 & 0.5 & 0.2 & 0 & 0.2 \\
\hline Igbo & 5.9 & 0.6 & 17.8 & 1.8 & 0.1 & 2 \\
\hline Yoruba & 12.6 & 0.6 & 21.9 & 1.9 & 0.6 & 4.7 \\
\hline Others & 1.1 & 0 & 4.5 & 0.9 & 0 & 0.5 \\
\hline Uncategorised & 0.5 & 0 & 0.8 & 0.3 & 0 & 2.6 \\
\hline
\end{tabular}

Fig. 4. The locations of ameloblastoma in the jaw in Nigerian patients. A, The locations of ameloblastoma in the jaw among different tribal groups. B, Heat map of the locations of ameloblastoma in the jaw among different ethnic groups. mand, mandible; $\max$, maxilla.

Table II. Distribution of ameloblastoma cases in different tribes

\begin{tabular}{lllll}
\hline Tribe & No. of cases & Percentage of cases & Mean age & Male-to-female ratio \\
\hline Edo & 24 & 1.9 & $28.54 \pm 11.76$ & $1.2: 1$ \\
Efik & 13 & 1.0 & $36.85 \pm 16.50$ & $1.6: 1$ \\
Fulani & 30 & 2.4 & $32.53 \pm 12.67$ & $1: 1.3$ \\
Hausa & 145 & 11.6 & $31.28 \pm 12.16$ & $1.4: 1$ \\
Ibibio & 15 & 28.3 & $29.80 \pm 14.90$ & $1.8: 1$ \\
Igbo & 352 & 42.1 & $31.89 \pm 14.75$ & $1.1: 1$ \\
Yoruba & 525 & 7.1 & $33.35 \pm 14.97$ & $1.2: 1$ \\
Others* & 89 & 4.3 & NA & NA \\
Uncategorized & 53 & & & \\
\hline
\end{tabular}

NA, not applicable.

*Tribes with fewer than 10 representatives and foreigners living in Nigeria. 
which is in line with previous findings of studies performed in different regions of the country. $6,8,20,21,30$

Although ameloblastoma is a benign tumor, it can grow to a large size, and its poor symptoms and late presentation often lead to late diagnosis and treatment. Delayed presentation of an orofacial tumor, such as ameloblastoma, is a common phenomenon in Nigeria. In a review of 156 cases of odontogenic tumors in Calabar, Nigeria, Anyanechi et al. ${ }^{10}$ reported a significant association between the size of tumor and the duration of symptoms prior to presentation; the longer the duration of symptoms before presentation, the larger was the tumor. Our findings indicate that there does not seem to be a plateau, but rather that a linear relationship with time exists, without any differentiation in the growth rate of the tumor (no slow or fast growing entities). Anyanechi et al. ${ }^{10}$ observed that the majority of patients $(91.7 \%)$ presented 1 to 12.5 years after they first noticed the lesion. Etetafia et al. ${ }^{12}$ reported similar findings in a case series from another part of the country and stated that fear of surgery, ignorance, and sociocultural beliefs are the common reasons patients present late for treatment. ${ }^{12}$ Because patients usually present late, it is very likely that the age of a patient at tumor onset is much younger than what is clinically recorded.

The location of ameloblastoma in the jaw seems to follow the same pattern in all tribes, with the posterior part of the mandible on the right being the most common site, followed by the posterior left mandible and the anterior mandible.

Few treatment options exist for the management of ameloblastoma. Resection with a safe margin is the best method of treating most ameloblastomas. ${ }^{24,31,32}$ Conservative surgical approaches are associated with high recurrence rates, such as " $22.2 \%$ and $29.3 \%$ ", compared with $3.8 \%$ and $4.5 \%$, respectively, when treated with segmental jaw resection. ${ }^{24,31}$ The large size of these tumors often leads to the need for an extensive surgical resection to ensure complete tumor removal and prevent or minimize recurrences. The nature of ameloblastoma is such that the border of the tumor within the cancellous bone lies beyond the apparent macroscopic surface and radiographic boundaries of the tumor. ${ }^{13,14,17,33}$ This informs surgical resection within normal tissue while accommodating a safe margin of resection. Hong et al. recommended that resection of the jaw should be approximately 1.5 to $2 \mathrm{~cm}$ beyond the radiologic limit of uninvolved bone. ${ }^{24}$ However, the complex anatomy of the head and neck region and proximity to vital structures present a challenge to ensuring this margin of safety. Facial deformity, malocclusion, and impaired mastication are common complications after treatment.

Nonsurgical therapies, such as radiotherapy, could be considered for treating ameloblastomas in patients with incompletely resectable tumors or those not amenable to resection. ${ }^{34}$ However, radiation therapy is generally not considered a valid treatment option because ameloblastomas have been considered radioresistant for decades. ${ }^{35}$ Furthermore, squamous cell maturation among tumor cells has been documented. ${ }^{36}$

Recent advances have led to the development of targeted therapies for the management of ameloblastoma. The use of BRAF V600E-inhibiting therapeutic agents, such as dabrafenib and trametinib, has been reported to reduce tumor volume of $B R A F$-mutated ameloblastomas. ${ }^{36,37}$ This has been documented to reduce tumor volume by as much as $90 \% .^{34,38}$ In addition to unresectable cases, targeted therapy can be beneficial in cases with residual tumors after surgical resection, cases (BRAF-mutated ameloblastoma) where the therapy shrinks the tumor size, thereby reducing the extent of subsequent jaw resection and metastasis, as illustrated by a case report that documented apparent tumor clearance of metastatic ameloblastoma in the lung. ${ }^{37}$

Like any other orofacial tumors, the objectives of treating amelobastoma are to remove the tumor, restore function and aesthetics, and prevent recurrence. These objectives are usually not achieved in most cases, especially when patients present late. Late presentation still remains the main challenge in the detection and management of maxillofacial tumors to improve patient quality of life postoperatively and reduce functional and cosmetic problems, such as malocclusion, masticatory dysfunction, abnormal jaw movement, and facial deformities.

An awareness campaign to educate the populace on the need for early presentation at treatment centers is necessary, especially at the primary health care level. ${ }^{18}$ A media campaign to enlighten people and help them overcome barriers created by fear of treatment and cultural beliefs will go a long way to encourage early presentation for treatment.

The institution of policies by the government and the efforts of nongovernmental organizations to promote health awareness and encourage routine annual checkups among particular age groups will enhance early tumor detection. Training dentists, maxillofacial surgeons, and other practitioners to recognize the early symptoms of orofacial tumors will result in early referral and diagnosis and, thus, effective management. 


\section{CONCLUSIONS}

Ameloblastoma occurs most commonly among young adults in Nigeria, and the mandible is the most common site of tumor, with the right side of the jaw being the preferred location.

Delayed presentation of an orofacial tumor, such as ameloblastoma, is a common phenomenon among all ethnic groups in Nigeria. As resection with a safe margin is the best method of treating most ameloblastomas, early detection and early initiation of treatment are important. An awareness campaign to educate the populace on the need for early presentation at treatment centers is necessary.

\section{REFERENCES}

1. Masthan KM, Anitha N, Krupaa J, Manikkam S. Ameloblastoma. J Pharm Bioallied Sci. 2015;7:S167-S170.

2. Arotiba JT, Ogunbiyi JO, Obiechina AE. Odontogenic tumours: a 15-year review from Ibadan, Nigeria. $\mathrm{Br} J$ Oral Maxillofac Surg. 1997;35:363-367.

3. Adebayo ET, Ajike SO, Adekeye EO. Odontogenic tumours in children and adolescents: a study of 78 Nigerian cases. $J$ Craniomaxillofac Surg. 2002;30:267-272.

4. Bassey GO, Osunde OD, Anyanechi CE. Maxillofacial tumors and tumor-like lesions in a Nigerian teaching hospital: an eleven year retrospective analysis. Afr Health Sci. 2014;14:56-63.

5. Iyogun C, Omitola O, Ukegheson G. Odontogenic tumors in Port Harcourt: south-south geopolitical zone of Nigeria. J Oral Maxillofac Pathol. 2016;20:190-193.

6. Lawal AO, Adisa AO, Olusanya AA. Odontogenic tumours: a review of 266 cases. J Clin Exp Dent. 2013;5:e13-e17.

7. Odukoya O. Odontogenic tumors: analysis of 289 Nigerian cases. J Oral Pathol Med. 1995;24:454-457.

8. Adebiyi KE, Ugboko VI, Omoniyi-Esan GO, Ndukwe KC, Oginni FO. Clinicopathological analysis of histological variants of ameloblastoma in a suburban Nigerian population. Head Face Med. 2006;2:42.

9. Ajagbe HA, Daramola JO. Ameloblastoma: a Survey of 199 Cases in the University College Hospital, Ibadan, Nigeria. J Natl Med Assoc. 1987;79:324-327.

10. Anyanechi CE, Saheeb BD. A review of 156 odontogenic tumours in Calabar, Nigeria. Ghana Med J. 2014;48:163-167.

11. Arotiba JT, Ogunbiyi JO, Obiechina AE. Odontogenic tumours: a 15-year review from Ibadan, Nigeria. Br J Oral Maxillofac Surg. 1997;35:363-367

12. Etetafia MO, Arisi AA, Omoregie OF. Giant ameloblastoma mortality: a consequence of ignorance, poverty and fear. BMJ Case Rep. 2014. 2014. pii: bcr2013201251.

13. Antonoglou GN, Sandor GK. Recurrence rates of intraosseous ameloblastomas of the jaws: a systematic review of conservative versus aggressive treatment approaches and meta-analysis of non-randomized studies. J Craniomaxillofac Surg. 2015;43:149-157.

14. Filizzola AI, Bartholomeu-dos-Santos TC, Pires FR. Ameloblastomas: clinicopathological features from 70 cases diagnosed in a single oral pathology service in an 8-year period. Med Oral Patol Oral Cir Bucal. 2014;19:e556-e561.
15. Zhong LP, Zhang ZY, Zhu HG, Fu HH, He Y. Clinical management of peripheral ameloblastoma. J Craniofac Surg. 2011;22:1929-1932.

16. Black CC, Addante RR, Mohila CA. Intraosseous ameloblastoma. Oral Surg Oral Med Oral Pathol Oral Radiol Endod. 2010;110:585-592.

17. Ghandhi D, Ayoub AF, Pogrel MA, MacDonald G, Brocklebank LM, Moos KF. Ameloblastoma: a surgeon's dilemma. J Oral Maxillofac Surg. 2006;64:1010-1014.

18. Lawal HS, Adebola RA, Arotiba JT, et al. Quality of life of patients surgically treated for ameloblastoma. Niger Med J. 2016;57:91-98.

19. Arotiba GT, Hille J, Guthua SW, Adeola H, Odhiambo W. Ameloblastoma in black Africans: the need for multi-national collaborative research. JSM Dent Surg. 2017;2:1014.

20. Arotiba GT, Ladeinde AL, Arotiba JT, Ajike SO, Ugboko VI, Ajayi OF. Ameloblastoma in Nigerian children and adolescents: a review of 79 cases. J Oral Maxillofac Surg. 2005;63:747-751.

21. Ladeinde AL, Ogunlewe MO, Bamgbose BO, et al. Ameloblastoma: analysis of 207 cases in a Nigerian teaching hospital. Quintessence Int. 2006;37:69-74.

22. Santos TS, Piva MR, Andrade ES, Vajgel A, Vasconcelos RH, Martins-Filho PRS. Ameloblastoma in the Northeast region of Brazil: a review of 112 cases. J Oral Maxillofac Pathol. 2014;18:S66-S71.

23. Chawla R, Ramalingam K, Sarkar A, Muddiah S. Ninety-one cases of ameloblastoma in an Indian population: a comprehensive review. J Nat Sci Biol Med. 2013;4:310-315.

24. Hong J, Yun PY, Chung IH, et al. Long-term follow up on recurrence of 305 ameloblastoma cases. Int J Oral Maxillofac Surg. 2007;36:283-288

25. Jing W, Xuan M, Lin Y, et al. Odontogenic tumours: a retrospective study of 1642 cases in a Chinese population. Int J Oral Maxillofac Surg. 2007;36:20-25.

26. Siar CH, Lau SH, Ng KH. Ameloblastoma of the jaws: a retrospective analysis of 340 cases in a Malaysian population. J Oral Maxillofac Surg. 2012;70:608-615.

27. Olaitan AA, Adeola DS, Adekeye EO. Ameloblastoma: clinical features and management of 315 cases from Kaduna, Nigeria. $J$ Craniomaxillofac Surg. 1993;21:351-355.

28. Philipsen HP, Reichart PA, Nikai H, Takata T, Kudo Y. Peripheral ameloblastoma: biological profile based on 160 cases from the literature. Oral Oncol. 2001;37:17-27.

29. LeCorn DW, Bhattacharyya I, Vertucci FJ. Peripheral ameloblastoma: a case report and review of the literature. $J$ Endod. 2006;32:152-154

30. Ajayi OF, Ladeinde AL, Adeyemo WL, Ogunlewe MO. Odontogenic tumors in Nigerian children and adolescents-a retrospective study of 92 cases. World J Surg Oncol. 2004;2:39.

31. Olusanya AA, Adisa AO, Lawal AO, Arotiba JT. Gross surgical features and treatment outcome of ameloblastoma at a Nigerian tertiary hospital. Afr J Med Med Sci. 2013;42: 59-64.

32. Effiom OA, Ogundana OM, Akinshipo AO, Akintoye SO. Ameloblastoma: current etiopathological concepts and management. Oral Dis. 2018;24:307-316.

33. Carlson ER, Marx RE. The ameloblastoma: primary, curative surgical management. J Oral Maxillofac Surg. 2006;64:484-494.

34. Koukourakis GV, Miliadou A, Sotiropoulou-Lontou A. Ameloblastoma, a rare benign odontogenic tumour: an interesting 
tumour review targeting the role of radiation therapy. Clin Transl Oncol. 2011;13:793-797.

35. Gardner DG. A pathologist's approach to the treatment of ameloblastoma. J Oral Maxillofac Surg. 1984;42:161-166.

36. Tan S, Pollack JR, Kaplan MJ, Colevas AD, West RB. BRAF inhibitor treatment of primary BRAF-mutant ameloblastoma with pathologic assessment of response. Oral Surg Oral Med Oral Pathol Oral Radiol. 2016;122:e5-e7.

37. Kaye FJ, Ivey AM, Drane WE, Mendenhall WM, Allan RW. Clinical and radiographic response with combined BRAF-targeted therapy in stage 4 ameloblastoma. J Natl Cancer Inst. 2014;107:378.

38. Faden DL, Algazi A. Durable treatment of ameloblastoma with single agent BRAFi Re: Clinical and radiographic response with combined BRAF-targeted therapy in stage 4 ameloblastoma. $J$ Natl Cancer Inst. 2016;109. pii: djw190.

Reprint requests:

Agbaje Jimoh Olubanwo

OMFS-IMPATH Research Group

Department of Oral and Maxillofacial Surgery

University Hospitals Leuven

Leuven

Kapucijnenvoer 33

Leuven 3000

Belgium

joagbaje@gmail.com 